organs are likely to deteriorate. It has been suggested that the difficulty can be avoided if the surgeons concerned with the transplantation are not called until those responsible for the injured patient are satisfied that he is dead, or at any rate that no possible hope of saving life remains. Owing to the shortness of the permissible interval between death and transplantation, however, the surgeons concerned with the transplantation must be given sufficient warning to enable them to make the necessary preparations for the operation, and those looking after the injured patient can scarcely fail to know that their unseen colleagues are waiting poised for action, or that their colleagues' patient is also waiting, hoping desperately for a graft that will give him a chance of survival.

The dilemma thus remains, however much we seek to apportion the responsibility, and I see no hope of escaping it entirely, but there are three ways in which the situation might be improved. In the first place, it would be helpful if people who want their organs to be available after death for purposes of transplantation should make this known to their next of kin, their doctors, and their legal advisers. Secondly, it should be possible to improve methods of resuscitation so that terminal deterioration of the kidneys and other vital organs is reduced to a minimum. Finally, it would help greatly if we were able to develop methods which could be instituted promptly after death for preserving tissues and organs in a viable state before the $y$ were removed from the body, thus avoiding the present necessity of having the prospective recipient ready and waiting to receive the graft.

It has been suggested that kidneys might also be obtained from those whose death is the result of judicial execution. For my part, I would reject this source entirely. In the first place, the number of such cadavers would, fortunately, be small, and I think it is extremely doubtful whether the authorities would agree to make them available. Secondly-and here, of course, I am simply expressing a personal opinion-I think it would be deplorable to do anything which might create a vested interest in such a barbaric practice as capital punishment.

\section{Experimental Work with Other Organs}

I have been speaking up to now of transplantation of the kidney. As you know, however, there has been a great deal of experimental work on transplantation of other organs, and attempts have already been made in a few cases to transplant the liver, lung, and heart to human patients. The technical problems here are indeed formidable, though I do not think they are insuperable. It is clear, however, that one cannot look to living volunteers for these organs, and, in the case of the liver in particular, the permissible interval between death of the donor and transplantation is even shorter than in the case of the kidney. All the various difficulties that we have been considering therefore arise in even more acute form.

I have left you with many questions, and only a few very sketchy answers. You may feel that it would have been better not to have raised these issues at all, but the fact of the matter is that, whether we like it or not, they raise themselves. In the practice of medicine there is no turning back, and not much opportunity for standing still. Medicine serves mankind, and the needs of our fellows drive us on.

The opinions expressed are my own, but I would like to record my deep gratitude to colleagues who have shared the responsibility of making decisions in all our cases of renal transplantation.

\section{REFERENCES}

Beecher, H. K. (1959). F. Amer. med. Ass., 169, 461

Brit. med. F., 1962, 2, 1108 .

Ethical Committee, World Medical Association (1962). Brit. med. F., 2, 1119.

Hill, Sir A. Bradford (1963). Ibid., 1, 1043.

Woodruff, M. (1963). Ibid., 1, 1339

\title{
Mortality in Relation to Smoking: Ten Years' Observations of British Doctors
}

\author{
Completion of article published last week, pp. 1399-1410
}

RICHARD DOLL, $\dagger$ M.D., D.SC., F.R.C.P. ; Sir AUSTIN BRADFORD HILL, $\ddagger$ C.B.E., F.R.C.P.(HON.), F.R.S.

Brit. med. F., 1964, 1, 1460-1467

\section{General Discussion}

In the preceding sections we have set out our observations. We turn now to their interpretation. We have to consider, as is true in nearly every problem of human epidemiology, observed associations-in the present instance between smoking habits and features of mortality. We have to decide from these associations, together with all other available evidence in man and animal, whether association implies causation.

In so doing we can consider our rates of mortality in at least two ways: (1) we can calculate the absolute difference between them, and (2) we can calculate the ratio of one to the other. For example, we have found death rates per 1,000 per annum from cancer of the lung of 0.07 in non-smokers, 0.93 in cigarette smokers, and 2.23 in cigarette smokers of 25 or more cigarettes

† Director of the Medical Research Council's Statistical Research Unit, University College Hospital Medical School, London. $\ddagger$ Emeritus Professor of Medical Statistics in the University of London. a day (Tables 23 and 24). With these figures we can say that the excess mortality in cigarette smokers over non-smokers has been 0.86 deaths per 1,000 and in heavy cigarette smokers over non-smokers 2.16 deaths per 1,000-that is, the absolute differences. Alternatively we can say that the death rate of cigarette smokers from cancer of the lung has been thirteen times the rate of non-smokers, and that the death rate of heavy cigarette smokers has been over thirty times the rate of non-smokersthat is, the ratios.

Both these ways of looking at the data are legitimate, both have their uses. If we wish to know how many extra deaths will result from smoking (presuming for the moment causation) then clearly we must calculate the absolute differences. We may, of course, find that quite a small proportional rise in mortality from a common cause of death, such as coronary thrombosis, has a greater effect upon total mortality than a pronounced rise for a less common cause, such as cancer of the lung. But, despite Berkson's (1959) opinion, it certainly does not follow that this best measure of the effect upon total mortality is also 
the best measure in relation to aetiology. Here the contrasts given by the ratios may be far more informative and convincing. Indeed, in many epidemiological investigations of the past the clue to aetiology lay in the pronounced ratio of the attack rates in consumers versus non-consumers of, for example, water or of foodstuff, and not in the absolute difference between their attack rates. That there were proportionately in the consumers 20 victims, say, to every one in the non-consumers stands out starkly. In general we shall follow that example. On this basis we have no associations to inquire into in the numerous causes of death, which comprise $60 \%$ of the total mortality. But, in contrast, in the remaining $40 \%$ there are seven causes (or groups of causes) which present a prima-facie case of cause and effect. Each of these we must examine separately.

\section{Cancer of the Lung}

With cancer of the lung our figures wholly confirm and, with larger numbers of deaths, strengthen those we have previously published. They also agree closely with those obtained by Hammond and Horn (1958) and by Dorn (1959) and with other studies summarized in the Report of the Advisory Committee to the Surgeon General of the U.S. Public Health Service (1964). With the larger numbers we now present, the approximately linear relation that emerges between mortality and number of cigarettes smoked daily is particularly striking (Fig. 1). There is no evidence here of any threshold that must be passed before a response in mortality takes place. On the other hand, there is evidence of so close a relation that it becomes increasingly difficult to envisage any other feature of the environment correlated with cigarette smoking as being the real and underlying cause. Equally striking and informative is the fall in mortality that rapidly follows the cessation of smoking. Unexpected as this may be at first sight, it is entirely consistent with the findings of Auerbach, Stout, Hammond, and Garfinkel (1962) on the pathological abnormalities to be seen in the bronchial epithelium of smokers and ex-smokers. Cells with "atypical nuclei comparable to the cells in lung cancer" were observed in $93 \%$ of their sections of the bronchi from 72 current cigarette smokers and in only $6 \%$ of the sections from 72 matched ex-cigarette smokers. Further, a peculiar type of cell with a disintegrating nucleus was seen in the ex-smokers and only in the ex-smokers, 43 of whom had these " unique cells."

This feature of an increasing fall in mortality with the passage of time since smoking was given up cannot, we believe, be explained in terms of genetics. If, on Fisher's (1957) hypothesis, the smokers who selectively choose to give up smoking are those who would in any event suffer a relatively low mortality from cancer of the lung, then this relatively low mortality should be an unchanging feature of the group. That would be their genetic fate at all points of time. Table 29, however, gives a very different picture. While the death rate of the continuing smokers from cancer of the lung is unchanged, we see in ex-smokers a rate of 0.41 per 1,000 during our first five years of observation which falls to 0.09 in the second fiveyear period. These results are amplified in Table 25 ; among continuing cigarette smokers the rate is 1.28 per 1,000 whereas among ex-smokers it is 0.67 within the first five years of giving up, 0.49 during the fifth to ninth year, 0.18 during the 10th to 19 th year, and 0.19 after 20 years or more. In terms of environment we can explain this sequence simply. We see the effects of exposure to an environmental factor diminishing the further one goes in time.

There is another feature of these data which refutes the argument that the excess of cancer of the lung in smokers compared with non-smokers is merely a feature of their differing genetic constitutions. During the 10 years of this inquiry the death rate from cancer of the lung of all men aged 25 and over in England and Wales has risen by $22 \%$ (from 1.04 per 1,000 in 1952-6 to 1.27 per 1,000 in 1957-61). On the other hand, looking at our population of male doctors as a whole we find that their mortality from cancer of the lung has fallen
(Table 11). Thus during the first five years, 1951-6, the death rate was 0.69 per 1,000 per annum, and during the second five years, 1956-61, it was 0.64 , a fall of $7 \%$-and this figure must understate the real change, since in the first year or two of the inquiry we know that the mortality we recorded was unduly favourable ${ }^{1}$ (see p. 1399). Since we are considering the whole population no selective factors can explain this change, and we believe it to be a reflection of the concurrent change in the doctors' smoking habits. Of the 31,208 men in 1951 roughly 17,500 were smoking cigarettes (alone or mixed); in 1958 the number had fallen to 13,500 (Table 1). Of those smoking cigarettes only in $1951,29 \%$ had decreased their amount in 1958 (including those who had given up entirely), $5 \%$ had switched to pipe and/or cigars, and only $2 \%$ had increased their smoking (Table 3).

Our data on inhaling are another new feature of this inquiry. In this respect we may recall that our retrospective investigations of patients and paired controls showed very little difference between them (Doll and Hill, 1952). In total (men and women) $64.6 \%$ of the patients with lung cancer and $66.6 \%$ of the patients with other diseases said that they inhaled, and similar results were found for men and women separately. Looking back, one feature that must have contributed to this equality was our inclusion of patients in the control group who were suffering from diseases that to-day we find are also affected by inhaling-for example, bronchitis. Still subject to this same defect, a later analysis by number of cigarettes smoked gave the results shown in Table $35 .^{2}$ With light and medium smokers we again find but little difference, while with the heavy smokers there is a drop in the proportion with cancer of the lung who said that they inhaled, and this is much less apparent in the controls.

TABLE 35.-Retrospective Inquiries Into the Frequency of Inhaling

\begin{tabular}{|c|c|c|c|c|}
\hline \multirow{2}{*}{$\begin{array}{c}\text { No. of } \\
\text { Cigarettes } \\
\text { per Day }\end{array}$} & \multicolumn{2}{|c|}{$\begin{array}{l}\text { Doll and Hill } \\
\% \text { Inhalers }\end{array}$} & \multicolumn{2}{|c|}{$\begin{array}{c}\text { Schwartz et al. } 1961 \\
\% \text { Inhalers }\end{array}$} \\
\hline & $\begin{array}{l}\text { Cancer of } \\
\text { Lung Patients }\end{array}$ & $\begin{array}{l}\text { Control } \\
\text { Patients }\end{array}$ & $\begin{array}{c}\text { Cancer of } \\
\text { Lung Patients }\end{array}$ & $\begin{array}{l}\text { Control } \\
\text { Patients }\end{array}$ \\
\hline \multirow{4}{*}{$\begin{array}{c}1-4 \\
5-9 \\
10-14 \\
15-19 \\
20-24 \\
25-29 \\
30+\end{array}$} & 50 & 48 & 50 & 29 \\
\hline & 81 & 79 & 59 & 46 \\
\hline & \{ & 82 & 61 & 46 \\
\hline & 62 & 71 & 60 & 72 \\
\hline
\end{tabular}

In the similar large-scale inquiry carried out in Paris by Schwartz, Flamant, Lellouch, and Denoix (1961) the results were different. They show a very large excess of inhalers in the cancer of the lung group in the light smokers. On the other hand, the excess diminishes with increased smoking, and, as in our own figures, is reversed at the highest level of smoking. Spicer (1964), in an extensive study carried out in conjunction with the British Tuberculosis Association, also found the same trend.

With our present prospective inquiry the numbers of deaths are so far small, but they also seem to indicate a hazard in inhaling at the lower levels of smoking and its disappearance at high levels. For this latter phenomenon we have no explanation. But there are, of course, many facets to smoking of which we are ignorant. Do, for instance, very heavy smokers who inhale smoke less of the cigarette? Does the heavy smoker inhale the smoke so deeply that it is deposited in the alveoli instead of in the bronchi (Davies, 1957)? And so on.

Such questions arise acutely, we have shown, in the comparison of the mortality of men with that of women. With a

${ }^{1}$ This feature must also contribute to the difference between the doctors and the general population in the first five years of the inquiry. Other factors will include a substantially higher proportion of nonsmokers among the doctors who replied to us and possibly other differences in smoking habits.

${ }^{2}$ These figures differ from those published by R. A. Fisher (1959), who, when we provided him with these data, used only those from the first half of our inquiry. 
bigher age of starting to smoke and far less inhaling in women, a'liwance made merely for the amount smoked is clearly insuffiicnt. Whether, therefore, cigarette smoking alone is adequate in account for the large sex difference in mortality remains upen to question; certainly it cannot be asserted that it is not.

One feature that is striking is the very low mortality in both sexes in non-smokers. With quite large numbers of doctors at risk we have seen in 10 years only three deaths from cancer of the lung in men and one in women. ${ }^{3}$ Most doctors in the Lnited Kingdom must practise in urban areas, and in the absence of smoking they have not derived cancer of the lung from the air pollution of the type and level to which they have been exposed in the last 50 to 60 years. This, of course, does not deny the possibility of some urban factor acting synergistically with smoking. What it does show is that in the absence of any smoking the rate would be only $11 \%$ of that actually prevailing. We cannot necessarily pass from doctors to the general population with its different smoking habits and some occupational hazards. The estimated death rate of our non-smoking doctors is, however, similar to the rates derived from other populations in other studies, including our own large retrospective inquiry (Doll and Hill, 1952 ; Doll, 1953). It seems probable, therefore, that without smoking the lung cancer mortality in England and Wales could also be at a similar low level.

We have already shown that a reduction of the present death rate would be likely to follow quite rapidly on a reduction in cigarette smoking.

How smoking exerts its effect remains open to doubt. Experimentally, applied to the skin of laboratory animals, the tar from

TAвLв 36.-Death Rate from Related and Unrelated Cancers by Smoking

\begin{tabular}{|c|c|c|c|c|}
\hline \multirow{3}{*}{$\begin{array}{c}\text { Age } \\
\text { (Years) }\end{array}$} & \multicolumn{4}{|c|}{ Death Rate per 1,000} \\
\hline & \multicolumn{2}{|c|}{$\begin{array}{c}\text { Cancer of Lung and Upper } \\
\text { Respiratory and Digestive Tracts }\end{array}$} & \multicolumn{2}{|c|}{$\begin{array}{l}\text { Other } \\
\text { Cancers }\end{array}$} \\
\hline & Non-smokers & Smokers & Non-smokers & Smokers \\
\hline $\begin{array}{c}25-29 \\
30-34 \\
35-39 \\
40-44 \\
45-49 \\
50-54 \\
55-59 \\
60-64 \\
65-69 \\
70-74 \\
75-79 \\
80-84 \\
85 \text { and over }\end{array}$ & $\begin{array}{c}\bar{Z} \\
0 \cdot 10(1) \\
= \\
= \\
\bar{z} \\
0.92(1) \\
2.34(2) \\
=\end{array}$ & $\begin{array}{c}\overline{-} \\
0.03(1) \\
0.08(3) \\
0.18(6) \\
0.69(21) \\
1.32(36) \\
2.52(51) \\
2.95(44) \\
2.94(34) \\
4.06(33) \\
4.52(22) \\
3.35(8)\end{array}$ & $\begin{array}{l}0.19(1) \\
0.20(2) \\
0.57(6) \\
0.24(2) \\
0.82(5) \\
0.66(3) \\
1.16(4) \\
1.76(4) \\
6.02(9) \\
2.75(3) \\
12.87(11) \\
16.46(10) \\
32.35(11)\end{array}$ & $\begin{array}{l}0.49(5) \\
0.23(6) \\
0.27(10) \\
0.39(15) \\
0.56(19) \\
1.18(36) \\
1.11(30) \\
2.82(57) \\
3.89(58) \\
6.41(74) \\
8.00(65) \\
12.92(63) \\
13.82(33)\end{array}$ \\
\hline 25 and over* & $0 \cdot 11(4)$ & $0.91(259)$ & $1.87(71)$ & $1.65(471)$ \\
\hline
\end{tabular}

- Standardized rates.

tobacco smoke is carcinogenic (Wynder, Graham, and Croninger, 1955), though not, it generally appears, very strongly so ; however, it has also a substantial promoting action (Roe, Salaman, and Cohen, 1959). If either of these observations is relevant, the latter may be the more important, since the rapid fall in the deaths from lung cancer on stopping smoking is similar to the reduction in skin cancers in animals when the application of a promoting agent is stopped (Pike and Roe, 1963 ; Roe and Clack, 1963). The suggestion that the

- It is very doubtful if one of them was in fact due to primary lung cancer. A man aged 79 presented with diarrhoea and loss of weight and was diagnosed by a consultant physician on the strength of a single chest $x$-ray examination as having a bronchogenic carcinoma. The $x$-ray films were submitted to us and we sought the opinions of two radiologists. Both reported independently that there were multiple rounded opacities in both lungs and that the lesions were most probably secondary to a primary cancer elsewhere. Of the most probablect basis of a three-months history of weakness, dyspnoea, cough, and blood-stained sputum; oedema appeared in the right leg after three weeks and death occurred two months later. A barium-meal examination was negative; a chest $x$-ray examination was refused. The two other diagnoses (in a man aged 37 and a woman aged 63) were confirmed histologically; in both cases the tumour was an oat-celled carcinoma. effect may merely be to hasten the appearance of cancer, in a "cancer prone" individual, and to localize it in a particular site (Goodhart, 1959) is not supported by the evidence. If such an effect exists there should be less cancer in other sites among smokers than among non-smokers. In fact, there is no evidence of this until after 75 years of age (Table 36). Moreover, other evidence from both family and industrial studies (Case, 1954 ; Murphy and Abbey, 1959 ; Hauge and Harvald, 1961) weighs heavily against the existence of any general " cancer proneness" in man.

\section{Cancers of the Upper Respiratory and Digestive Tracts}

This group includes several different types of cancer which vary in their incidence in different populations independently, it appears, of one another. They are likely, therefore, to have different causes. Yet there is much evidence to suggest that most of them are to some extent related to tobacco consumption in one form or another. This relation has been demonstrated repeatedly in retrospective studies of patients and is borne out in all the prospective studies reviewed by the Surgeon General's Advisory Committee. However, unlike lung cancer, the association is less characteristic of cigarette smoking, and, indeed, in several studies the relationship is equally close, or closer, with the smoking of pipes or cigars. In the present study we have too few deaths to examine each of the sites separately, but, taking the group as a whole, our results agree with those of other studies and indicate that these cancers are about five times as common in smokers as in non-smokers.

Whether this observation should be interpreted to mean that such cancers are caused by smoking is, however, open to doubt. That they may be would seem to follow from the fact that tobacco smoke must pass through the mouth and larynx before it reaches the bronchi, and that in the bronchi it is carcinogenic. Two pieces of evidence, however, weigh against it. First, the mortality from some of these cancers has fallen in recent years, whereas the consumption of tobacco and the mortality from lung cancer have both risen. For example, between 1942 and 1962 , while the number of deaths attributed to lung cancer in England and Wales rose by $325 \%$, the number attributed to oesophageal cancer rose by only $8 \%$ and the numbers attributed to laryngeal cancer and to cancer of the oral cavity and pharynx fell by $22 \%$ and $36 \%$ respectively. Such wide differences cannot be explained by different trends in the fatality rate, nor, we think, by a differential change in the standards of diagnosis. To some extent they may be due to a change in the way tobacco has been smoked (from pipes to cigarettes). We do not know enough about the mechanism and time relations of cancer induction to estimate any possible effect of this change, but it is difficult to belive that it is the whole explanation.

Secondly, all these cancers have been reported as closely related to alcohol consumption, and this alone must result in some association with smoking, since heavy drinkers tend also to be heavy smokers (see p. 1465). In this respect it is perhaps notable that our results show that the excess mortality among smokers as a whole is largely due to a greatly increased mortality among the heavy smokers, a situation similar to that observed for the 33 deaths attributed to cirrhosis of the liver or alcoholism. We sought no data on alcohol consumption in our study, and thus it is impossible to assess the effect of the two factors separately. However, according to Schwartz, Denoix, and Anguera (1957) and to Wynder and Bross and their colleagues (Wynder, Bross, and Day, 1956 ; Wynder, Bross, and Feldman, 1957 ; Wynder and Bross, 1961), who have made detailed retrospective studies of patients with all of these cancers, alcohol and tobacco both exert independent effects. According to Wynder and Bross the effect of alcohol is unlike that of smoking, in that it is not proportional to the amount drunk, but is principally concentrated on heavy drinkers. If that be so, it might account for much of the 
discrepancy in the trends in the death rates from the different cancers.

On present evidence the most reasonable conclusion is that tobacco and alcohol both play some part in their production, but the two factors are correlated and it is not possible to estimate their separate effects quantitatively.

\section{Chronic Bronchitis}

The association of chronic bronchitis and emphysema with smoking that we observe in doctors has been a conspicuous feature of other prospective as well as retrospective studies and also of carefully conducted surveys of various populations. Thus, bringing together the results of seven prospective studies (including our own), the Surgeon General's Advisory Committee calculates that cigarette smokers died of chronic bronchitis and emphysema six times more frequently than nonsmokers (546 observed deaths to only 89 expected). In all but one of these studies the excess is marked.

As an example of a retrospective study we may cite the comparison made by Oswald, Harold, and Martin (1953) of 300 chronic bronchitics with 300 controls of similar age, sez, and social status. Of the latter, $21 \%$ reported themselves as non-smokers compared with only $9 \%$ of the former. These findings have been strongly supported by surveys of specific and general population groups in which smokers compared with non-smokers have been found to have more frequent respiratory symptoms, more frequent chest illnesses, and, on average, a diminished respiratory efficiency-for example, Higgins (1957), Olsen and Gilson (1960), Fletcher and Tinker (1961), Anderson and Ferris (1962); for a full review see the reports of the Royal College of Physicians (1962) and the Surgeon General's Advisory Committee.

'There is undoubtedly also good evidence in this country associating chronic bronchitis with air pollution independently of smoking-for example, Reid and Fairbairn (1958). Clearly the two characteristics may act independently or, perhaps more probably, synergistically. However that may be, the strong evidence on smoking has led Fletcher and Tinker (1961) to suggest that it is not unreasonable to conclude that cigarette smoking is one of the more important aetiological factors in chronic bronchitis in Great Britain. The death rates we have found in this present inquiry in doctors are certainly in keeping with this concept of the disease. Thus we have the very marked gradient in mortality with increasing amount smoked (Table 17), we have its concentration on cigarette smokers (Table 16), we have a higher death rate in inhalers (Table 32), and we have, after the initial period of self-selection, a decline in mortality after the giving up of smoking (Tables 25, 26, and 30). We may note also that the relationship, as would be anticipated, is less marked for those deaths in which chronic bronchitis was mentioned as only a contributory and not the underlying cause.

Finally, the thesis is supported by both histological and experimental evidence. Auerbach and his colleagues (1961, 1962, 1963), for example, found frequent epithelial changes in the bronchial tree and alveoli of cigarette smokers, and Hilding (1956) and Ballenger (1960), among many others, found that cigarette smoke had an inhibitory effect on human and on animal respiratory cilia. Taking all this evidence into account, we conclude that there is here, as with cancer of the lung, a direct causal relationship between smoking and mortality.

That being so, and seeing that chronic bronchitis is a common disease in this country, we must naturally anticipate the clinical finding that chronic bronchitis and cancer of the lung will quite frequently occur together in the same person. It is, of course, possible that the chronic bronchitis itself plays a part in producing cancer of the lung (Case and Lea, 1955), and figures published in a retrospective inquiry by Campbell and Lee (1963) somewhat support that view. For the prospec- tive inquiry, however, what we need is to observe the incidence of cancer of the lung in non-smokers suffering from chronic bronchitis; and with its rarity in the absence of smoking the problem is to obtain enough of them.

\section{Pulmonary Tuberculosis}

The relationship between smoking and mortality from pulmonary tuberculosis is quite distinct, though it is based, we should observe, upon only 42 deaths. The further 14 deaths in which the presence of the disease was mentioned as a contributory and not as the primary cause of death reveal no such association. It is therefore possible that smoking may hinder recovery from the infection or, as Lowe (1956) has concluded from his retrospective survey, it may conceivably re-aggravate a quiescent lesion. We see nothing unlikely in that. On the other hand, Kissen (1960a) suggests that anxiety is one reason for a poor prognosis in tuberculosis and also one reason for smoking. Without, therefore, more-and more precise-data on a disease so influenced by social factors, we hesitate to conclude that a direct causal relationship of mortality with smoking does exist.

\section{Coronary Thrombosis}

Deaths attributed to coronary disease amount, in our data, to $30 \%$ of the total deaths $(1,376$ out of 4,597$)$. The great majority are described as due to coronary thrombosis or myocardial infarction, but there is a small proportion described less specifically as due, for example, to "coronary-atheroma," "coronary ischaemia," or "angina pectoris with myocardial degeneration." With so many deaths it was not practicable to check the diagnoses as we did with cancer of the lung, and it is probable that many of them, particularly at ages over 75 years, were not, in fact, associated with an acute episode of thrombosis.

In 89 instances (6\% of the total) hypertension was also mentioned on the certificate, and these cases, examined separately, showed no relationship with smoking (Tables 18 and 19).

For the remaining 1,287 deaths the results are very similar to those we previously reported with less than half the number of cases (Doll and Hill, 1956), and, although the differences in mortality between cigarette smokers and non-smokers (33\%) and between heavy and light cigarette smokers (14\%) are not great, the numbers are so large that there can be no doubt that the relationship with cigarette smoking is not due to chance $(P=0.001$ and $P=0.04$ respectively). The results are, moreover, similar to those obtained in the six other large prospective studies reviewed by the Surgeon General's Advisory Committee, all of which show that the observed mortality from coronary disease among cigarette smokers is from 1.7 to 2.0 times the mortality expected from the experience of the nonsmokers. Similar results have also been obtained in Albany and Framingham by Doyle, Dawber, Kannel, Heslin, and Kahn (1962), who followed 4,120 initially healthy men and found that the incidence of myocardial infarction was 2.4 times higher in cigarette smokers than in non-smokers and 1.3 times higher in men smoking more than 20 cigarettes a day than in men smoking less. In all these studies as well as in our data the relationship is specific for cigarette smokers, and no excess mortality has been observed among pipe or cigar smokers.

According to Hammond and Horn (1958) and to Buechley, Drake, and Breslow (1958), the relationship is more marked at younger ages than at old. In our data this feature is distinct (Table 20) and the 38 deaths that occurred at the early age of 35-44 years show a relationship with smoking that is only a little less close than that for chronic bronchitis. At these ages the mortality among non-smokers is extremely low $(0.11 \mathrm{per}$ 1,000 per year), so that although the rate of 0.61 among cigarette 
smokers is only 0.50 per 1,000 higher the ratio of the rates is $5 \frac{1}{2}$ to 1 . Over the next four decades the mortality of nonsmokers increases to 10.83 and of smokers to 14.69 ; in other words, though the ratio of the rates has become quite small, the excess mortality of 3.86 is seven times the excess at ages 35-44 years. At the oldest ages (75 years and over) the difference between smokers and non-smokers disappears, but here the accuracy of many of the certified causes of death must be in serious doubt.

As with the other related diseases the mortality is lower among cigarette smokers who have stopped than among those who have continued, and, although the difference appears to be substantial, it has been shown that much of it may be an artifact, due merely to the selective failure of doctors to give up smoking when they are already ill (see p. 1408). When, to correct for this selection, the data for the first five years after stopping are omitted the results are less impressive. There is still evidence of a reduction in mortality, but the maximum effect is reached only slowly. Five to nine years after stopping the excess mortality has been reduced to $60 \%$ of that among continuing smokers, 10 to 19 years after to $38 \%$, and 20 or more years after to $29 \%$ (Table 25). Hammond and Horn (1958) also found a reduction in mortality with the passage of time after smoking had been stopped, and Doyle et al. (1962), studying men who were initially free from heart disease, found the subsequent incidence of myocardial infarction to be the same in both ex-smokers and non-smokers. The number of cases in their study was, however, small.

If the reduction in mortality is due to stopping smoking it would seem from these data that the effect takes place only slowly and over a long period of years. Many people, however, eat more when they stop smoking, and it is possible that the effect may be complicated by the effect of changing weight.

Our data on inhaling are still few, being based on only four years' observations, and the results are correspondingly unreliable. So far as they go they suggest that the mortality is higher among inhalers than among non-inhalers, but the difference is small and it is not statistically significant (Table 31). Schwartz, Anguera, and Lenègre (1961), on the other hand, carried out a retrospective study on nearly 1,000 patients with coronary atherosclerosis and found a highly significant excess of inhalers over a matched control series. Their data suggested that there was practically no difference in risk between non-inhalers and non-smokers and that the risk for heavy cigarette smokers could be almost entirely attributed to the fact that heavy smokers also tended to inhale.

The evidence from all these studies, therefore, is compatible with the belief that cigarette smoking is one of the causes of coronary thrombosis, and, in particular, one of the more important causes under 55 years of age. That it has an effect on the cardiovascular system is undisputed-the effect being probably due to the action of nicotine on the sympathetic ganglia or on the chromaffin cells, liberating noradrenaline and adrenaline. Even one or two cigarettes can increase the heart rate by $15-25$ beats a minute, raise the blood-pressure by $10-20 \mathrm{~mm}$. $\mathrm{Hg}$, and increase both the stroke volume and the cardiac output. The skin blood-flow is reduced, but the coronary flow is either increased or, with regular smoking, held stationary. Why these effects should be harmful is less clear. Smoking does not precipitate pain in the great majority of patients with angina pectoris, and true cases of tobacco angina (Pickering and Sanderson, 1945; Oram and Sowton, 1963) are so rare that it is difficult to believe that they provide a model for the substantial mortality that is apparently related to smoking.

It is, however, possibly more relevant that smokin may also have an effect on the level of serum lipids and on the control of intravascular coagulation. Many investigators have found that the serum cholesterol is, on average, higher in cigarette smokers than in non-smokers ${ }^{4}$; only two studies have been negative-one limited to young men who could not have smoked for more than a few years (Konttinen, 1962) and the other to men over 65 years of age (Acheson and Jessop, 1961). No change in serum cholesterol is, however, found immediately after smoking, the immediate effects being a decrease in serum triglycerides and an increase in free fatty acids (Kerschbaum, Bellet, Dickstein, and Feinberg, 1961; Konttinen and Rajasalmi, 1963). No effect has been noted on blood coagulation, but Mustard and Murphy (1963) found that smoking had an effect on the blood platelets, decreasing their duration of survival in vivo.

Alternatively, cigarette smoking and coronary thrombosis may be related to one another only indirectly through some other factor. It may be, for example, that men with a raised serum cholesterol or of a particular physical constitution (Seltzer, 1963) or who tend to take little physical exercise also tend to take up cigarette smoking, and that these factors contribute to the production of the disease. Such a hypothesis is not, at first sight, unattractive, since the ratio of the mortality rate of smokers to non-smokers is relatively small. But it becomes difficult to accept when all the evidence is taken into accountnamely, the much closer relationship at young ages, the increase in mortality with increased amount smoked, the difference between cigarette and pipe smoking and between inhaling and not inhaling, the reduction in mortality with increasing time after smoking has been stopped, and the many physiological effects of smoking on the cardiovascular system. In short, that cigarette smoking is a cause of coronary thrombosis is not, we think, proved ; but it is the most reasonable interpretation of the available facts.

\section{Peptic Ulcer}

Even including 15 deaths in which peptic ulcer was certified as being contributory though not the underlying cause, the total number (54) is too small to allow us to examine gastric and duodenal ulcers separately. Classed together as peptic ulcer, the results agree with those of 12 other studies in which the relationship between smoking and peptic ulcer has been specially examined (five retrospective, six prospective, and one cross-sectional survey, Surgeon General's Advisory Committee). In all the retrospective studies the proportion of non-smokers was higher in the control group than in the ulcer group, and in all the prospective studies the mortality was higher in smokers than in non-smokers. In all studies in which gastric and duodenal ulcers have been separated the relationship has been stronger with gastric ulcer than with duodenal, and, when the type of smoking has been examined, the relationship has been closer with cigarette smoking than with the smoking of pipes or cigars.

An unusual feature of the prospective studies has been that the mortality has been maximum in the moderate or light smokers rather than in the heavy cigarette smokers. This is shown in the present data (Table 22), and a comparable result was obtained in the one large-scale retrospective study in which this aspect was examined in detail (Doll, Jones, and Pygott, 1958).

It is difficult to believe that these findings mean that smoking is a direct cause of gastric ulcer, since gastric ulcers have been decreasing in incidence over the long period of time in which cigarette smoking has been increasing. Duodenal ulcers, admittedly, have increased in incidence, but with them the relationship with smoking is less close. The world-wide distribution of gastric and duodenal ulcers is also quite unlike the distribution of cigarette smoking. If, therefore, smoking is a direct cause it is only one among many and not the most important. The excess mortality could, of course, be obtained if smoking affected the fatality of the disease without affecting

\footnotetext{
- References are given by the Surgeon-General's Advisory Committee and by Konttinen and Rajasalmi (1963).
} 
its incidence-if, for example, it increased the risk of respiratory complications following operation. This, however, could not account for the excess morbidity. An alternative explanation would be that smoking habits are affected by the disease or result from the same factors as give rise to the disease. Thus many physicians believe that psychic factors play a part in producing ulcers, and there is evidence to suggest that they are also related to cigarette smoking (Lilienfeld, 1959 ; Eysenck, Tarrant, Woolf, and England, 1960 ; Kissen, 1960b). It is reasonable also to attribute the concentration of deaths among moderate smokers to a reduction, for medical reasons, in the amount smoked.

On the other hand, not all physicians are impressed by the importance of psychic factors in producing peptic ulcers, and few would suggest that they were more important in gastric than in duodenal ulcers. There is, moreover, one piece of evidence to suggest that smoking has a direct effect on the healing of gastric ulcers. Doll et al. (1958) carried out a controlled clinical trial on 80 patients and found that the ulcer healed, on average, by $78 \%$ of its initial size in those who were advised to stop smoking and by only $57 \%$ in those who were not so advised and all of whom continued to smoke.

From this we conclude that smoking plays some part in preventing the healing of a chronic gastric ulcer and that it may thereby have an effect on the mortality rate, both by maintaining the activity of the ulcer and by adversely affecting the fatality rate in the presence of complications. Some of the association, however, may well be secondary and of no aetiological significance, particularly, perhaps, with duodenal ulcer.

\section{Cirrhosis of the Liver and Alcoholism}

These two conditions show a close association with smoking, most marked with cigarettes and particularly with the smoking of more than 25 a day. We know of no evidence from retrospective studies, but the six other prospective studies in Canada and the U.S.A. all agree in showing an increased mortality in smokers compared with non-smokers (range 1.3 to 1 to 4.0 to 1 , Surgeon General's Advisory Committee). It is conceivable that very heavy smoking may exert a toxic effect on the liver-particularly, perhaps, if the liver is already damaged by other agents-but it seems more likely that the association with cirrhosis is secondary to an association with alcoholism. Several studies have shown that heavy drinkers tend also to be heavy cigarette smokers (Wynder et al., 1956, 1957 ; Heath, 1958), but without precise figures and an estimate of the proportion of cases that are due to alcoholism in Britain it is impossible to test the hypothesis.

\section{Other "Unrelated" Diseases}

With the large group of other and " unrelated" diseases the death rates of all the smoking subgroups lie, with one exception, in the narrow range of 8 to 9 per 1,000 (non-smokers 8.53, cigarette smokers 8.99 , mixed smokers 8.00 , pipe and/or cigar smokers 8.06, ex-cigarette smokers $8.02,1-14$ cigarettes daily $8.96,15-24$ cigarettes daily $8.66,25$ + cigarettes daily 10.11 ; Tables 23 and 24). This close similarity makes it unlikely that we have overlooked any major relationship between smoking and mortality. The only departure from the prevailing pattern is the rather high death rate of 10.11 per 1,000 in the heaviest cigarette smokers, an excess of $19 \%$ over the rate for non-smokers. This excess comes from only 7 of the 11 causes of death shown in Tables 23 and 24 , and could, we believe, be partly due not to smoking per se but to other features of life, both environmental and constitutional, which are correlated with it-for example, the psychological and possibly physical characteristics of heavy smokers and their habits of eating and drinking, etc. It is also likely that some of the excess is due to errors in the certification of the cause of death. Unless
$100 \%$ accuracy was achieved in death certification-and we know that it is never so-the "unrelated" causes must inevitably include some deaths that should in fact have been classified as related. The "unrelated" causes will thereby share some of the excess mortality of heavy cigarette smokers that is characteristic of the related causes. In short, we conclude that smoking bears no direct or causal relationship to some $60 \%$ of the total death rate.

That is not to say that our related causes necessarily include all the diseases in which smoking is of direct aetiological importance. We have no evidence on non-fatal diseases such as tobacco amblyopia, and very little for many rare diseases or diseases with a low fatality rate. There is, for example, strong evidence to inculpate smoking as a cause of thromboangiitis obliterans (Buerger's disease), but in our data no deaths were attributed to it.

Paucity of cases may also be the explanation of our failure to find any association of smoking with cancer of the bladder. Four retrospective studies have shown an increased mortality for this site among cigarette smokers-of the order of two to three times the rate in non-smokers-and a still higher rate of mortality in heavy cigarette smokers (Lilienfeld, Levin, and Moore, 1956 ; Schwartz et al., 1961 ; Lockwood, 1961 ; Wynder, Onderdonk, and Mantel, 1963). Moreover, similar results have been obtained in all the other six prospective studies (Surgeon General's Advisory Committee). Our data are based on only 38 cases-six of which occurred in non-smokers-and with this small number of deaths it would not be surprising if by chance we had failed to demonstrate a weak association with cigarette smoking. But it does not appear that there can be a strong relationship. (Since the conclusion of the ten-year period of observation a further 14 deaths with bladder cancer have been reported-six among cigarette smokers, eight among other smokers, and none in non-smokers.)

In the studies of Hammond and Horn (1958) and Dorn (1959) several other broad groups of diseases have also been reported to show an excess mortality with smoking. The excesses have mostly been quite small, and, with the exception of a heterogeneous group of "other circulatory diseases" (Surgeon General's Advisory Committee), none have consistently shown a mortality among cigarette smokers as much as double that among non-smokers. Such differences, we believe, could easily be due to the same causes as we have suggested above may account for the excess mortality from "unrelated" diseases in doctors who are heavy cigarette smokers. We may also note that the very large populations studied by Hammond and Horn (1958) and by Dorn (1959) have necessarily been heterogeneous in many respects. Their results may thereby be influenced to some extent by the social distribution of smoking. Doctors, on the other hand, are a more homogeneous group of one social class and one profession. Environmental factors that may be associated with smoking in the population at large will play a less important part. Further, the cause of death may be more accurately assessed among doctors, so that spurious associations due to errors in certification will be less likely to arise.

Finally, we have found no evidence of any cause of death the rate of which is lessened by smoking. There were, of course, several diseases in which the mortality was lower among smokers than among non-smokers, but in no case was this difference statistically significant and none showed a progressive decrease with increase in the amount smoked. This was slightly surprising, as morbidity studies have provided consistent evidence that the average blood-pressure is lower among cigarette smokers than among non-smokers (Brown, McKeown, and Whitfield, 1957 ; Karvonen, Orma, Keys, Fidanza, and Brozek, 1959; Edwards, McKeown, and Whitfield, 1959 ; Miall, 1960 ; Thomas, 1960). Yet, in our data, the mortality from hypertension was remarkably similar in all the categories of smokers and non-smokers. In the corresponding American studies (Surgeon General's Advisory Committee) the mortality 
was either unaltered or was slightly higher among smokers. Evidently, therefore, if smoking reduces the casual bloodpressure it does not affect the pressure sufficiently to have any measurable effect upon the death rate.

\section{Mortality Attributable to Smoking}

It was shown in Tables 23 and 24 that the annual death rate of cigarette smokers, including both those continuing and those giving up, was $29 \%$ greater than that of non-smokers ; in men who were continuing to smoke cigarettes at the start of the inquiry it was $35 \%$ greater. These figures, we pointed out, do not necessarily mean that cigarette smoking increases the death rate by such amounts, since other explanations are possible. However, after our separate and detailed examination of the principal causes of death we have concluded that cigarette smoking is likely to be responsible for at least the greater part of the excess.

The results of our assessment are summarized in Table 37, where we divide the excess death rate in smokers of different ages into three categories. (1) The first category comprises the excess deaths from the " unrelated" diseases and from cirrhosis of the liver and alcoholism. Conceivably some small part of this excess may be due to cigarette smoking, in so far as it is due to errors in the diagnosis of the cause of death; the

\begin{tabular}{|c|c|c|c|c|c|}
\hline \multirow{3}{*}{$\begin{array}{c}\text { Age } \\
\text { (Years) }\end{array}$} & \multicolumn{5}{|c|}{ Death Rate per 1,000} \\
\hline & \multirow[b]{2}{*}{$\begin{array}{l}\text { Non- } \\
\text { smokers }\end{array}$} & \multicolumn{3}{|c|}{ Excess Among Cigarette Smokers } & \multirow[b]{2}{*}{$\begin{array}{l}\text { Cigarette } \\
\text { Smokers } \\
\text { All Causes }\end{array}$} \\
\hline & & $\begin{array}{l}\text { Causes Not } \\
\text { Attributable } \\
\text { to Smoking }\end{array}$ & $\begin{array}{l}\text { Causes Partly } \\
\text { Attributable } \\
\text { to Smoking }\end{array}$ & $\begin{array}{c}\text { Causes } \\
\text { Attributable } \\
\text { to Smoking }\end{array}$ & \\
\hline $\begin{array}{l}25-44 \\
45-54 \\
55-64 \\
65-74 \\
75+\end{array}$ & $\begin{array}{r}1 \cdot 12 \\
4.12 \\
12.08 \\
30 \cdot 56 \\
114 \cdot 29\end{array}$ & $\begin{array}{r}0.48 \\
1.02 \\
2.37 \\
6.72 \\
-11.64\end{array}$ & $\begin{array}{l}0.04 \\
0.22 \\
0.92 \\
0.82 \\
2.09\end{array}$ & $\begin{array}{r}0.39 \\
2 \cdot 25 \\
5 \cdot 33 \\
10 \cdot 87 \\
6 \cdot 64\end{array}$ & $\begin{array}{r}2.04 \\
7.62 \\
20 \cdot 70 \\
48.96 \\
111 \cdot 37\end{array}$ \\
\hline $\begin{array}{l}\text { All ages } \\
\text { standardized }\end{array}$ & 12.06 & 0.93 & 0.40 & 2.93 & $16 \cdot 32$ \\
\hline $\begin{array}{l}\text { Percentage of } \\
\text { non-smokers }\end{array}$ & 100 & 8 & 3 & 24 & 135 \\
\hline
\end{tabular}

greater part, however, is likely to be either an artifact (due to the selective failure of doctors to stop smoking when they develop a serious illness; Table 25 and p. 1408), or a secondary effect of the association of cigarette smoking with some other factor which itself predisposes to disease and death -for example, heavy drinking or excessive anxiety. (2) The second category includes deaths from cancers of the upper respiratory and upper digestive tracts, from peptic ulcer, and from pulmonary tuberculosis. Some of these deaths are, we suggest, directly attributable to smoking, but it is impossible to say how many, since the effect of smoking is complicated by other factors, environmental and constitutional, with which it is associated. (3) The third and largest category includes deaths from lung cancer, chronic bronchitis, and coronary thrombosis. The first two, we conclude, are the direct result of the habit. With coronary thrombosis we feel less certainty, but at ages under 65 years we believe it only reasonable to regard smoking as the dominant factor. That being so, Table 37 shows that during the ages of 45-54 and 55-64 years approximately $50 \%$ is added to the death rate by smoking. One of the most striking characteristics of British mortality in the last half-century has been the relatively poor improvement in the death rate of men of ages 45-64 years. In cigarette smoking may, it seems, lie one prominent cause.

We have not made similar calculations for pipe or cigar smokers, since their total death rate is only $1 \%$ more than that of non-smokers in our inquiry and is only slightly raised in the four other prospective studies which provide these data. Thus the combined figures for all five studies show an excess death rate of only $6 \%$ (Surgeon General's Advisory Committee). Our examination of the separate causes of death, in the light of the findings for cigarette smokers, suggests, however, that pipe smoking is probably responsible for some cases of cancer of the lung and of the upper respiratory and digestive tracts and of chronic bronchitis. For these three causes of death we report an excess mortality in pipe and cigar smokers of 0.58 per 1,000 per annum, which is more than the total excess from all causes (0.17). The deficiency of deaths among pipe and cigar smokers compared with non-smokers for all other causes of death (0.41) may well be due to chance $(\mathbf{P}=0.4)$, but it is possible that pipe smokers also differ from non-smokers in other ways that tend to reduce their mortality. We cannot be sure, therefore, that a change in the method of smoking from cigarettes to pipes or cigars would necessarily result in as large a reduction in the death rate as would appear from the present figures-particularly if the ex-cigarette smokers were to continue to inhale (Table 30).

\section{Summary}

The mortality of nearly 41,000 medically qualified men and women in the United Kingdom has been observed for twelve years.

During the first ten years 4,597 of the men and 366 of the women died. These deaths have been analysed in relation to the smoking habits reported by doctors in reply to a questionary dispatched to them in 1951 (both sexes) and again in 1957 (men) and 1960 (women).

An association with smoking is found, in differing degrees, in men for seven causes of death-namely, cancer of the lung, cancers of the upper respiratory and digestive tracts, chronic bronchitis, pulmonary tuberculosis, coronary disease without hypertension, peptic ulcer, and cirrhosis of the liver and alcoholism. No association is found with the remaining $61 \%$ of the death rate, and this includes such major causes as other forms of cancer, cerebrovascular accidents, hypertension, myocardial degeneration, suicide, and accident.

In women the few deaths at present available show an association only between smoking and cancer of the lung.

The most pronounced association is shown by cancer of the lung for which the annual death rate rises linearly from 0.07 per 1,000 in men who are non-smokers to 3.15 per 1,000 in men smoking 35 or more cigarettes daily. This linear rise from non-smokers to light smokers to medium smokers to heavy smokers indicates no smoking threshold which must be reached before the death rate from cancer of the lung shows a response.

In men who have given up cigarette smoking the death rate from cancer of the lung falls substantially. It continues to fall step by step the longer smoking has been given up. This trend can be explained in terms of a diminishing risk from the previously operative environmental agent, but not in terms of genetic selection of those who choose to give up.

Between 1952 and 1961 the death rate from cancer of the lung in all men aged 25 years and over in England and Wales increased by $22 \%$. In the doctors here studied it has slightly declined (7\%) between 1951-6 and 1956-61, and this fall can be attributed to the concurrent change in their smoking habits. Many have given up smoking and many have reduced their consumption.

The very low death rate from cancer of the lung in nonsmokers of both sexes in a population that must live largely in urban areas does not suggest that air pollution per se has been an important factor in the production of the disease. Whether smoking acts synergistically with air pollution upon the respiratory tract is not known.

Mortality from cancer of the lung is certainly not closely associated with pipe smoking, but it does not appear that pipe smoking is entirely without risk. 
The death rate from cancer of the lung is higher for light and medium smokers who inhale than for those who do not inhale. With heavy smokers this extra hazard is not apparent.

With cancers of the upper respiratory and digestive tracts the association with smoking is not specific to cigarette smoking, and the excess mortality of smokers in these present observations of British doctors is mainly due to a greatly increased death rate of the heavy smokers. Taking all evidence into account the most reasonable conclusion would appear to be that tobacco and alcohol consumption both play some part in their production.

Though there is good evidence that in this country air pollution plays some part in the aetiology or aggravation of chronic bronchitis, the association of the disease with smoking has been a conspicuous feature of nearly every form of inquiry. As with cancer of the lung, there is no reason to doubt that there is a direct and important causal relationship between smoking and mortality.

The relationship between smoking and mortality from pulmonary tuberculosis is distinct, but with a disease so influenced by social factors more precise data are needed to justify a direct cause and effect hypothesis.

In the group of diseases and conditions leading to cardiovascular mortality the only cause associated with smoking habits is coronary disease without hypertension, of which the excess mortality is limited to cigarette smokers (a death rate $33 \%$ greater than the death rate of non-smokers) ; this association is marked at ages under 55 but it disappears at ages over 75 (where errors in diagnosis may be relatively frequent).

A reduction in coronary disease follows the giving up of smoking but appears to do so somewhat slowly.

The evidence from this and other studies supports the belief that cigarette smoking is one of the causes of coronary thrombosis under the age of 75 .

Though the association between smoking and mortality from peptic ulcer is significant it is not very close, and some part of it may well be secondary to other factors, either constitutional or environmental. There is, however, evidence that continued smoking may prevent or delay the healing of a chronic gastric ulcer and thereby it may increase the mortality rate.

Mortality from alcoholism and cirrhosis of the liver is specially high in heavy smokers. Heavy drinkers tend to be also heavy cigarette smokers, and this may well be the explanation of the increased death rate.

With the large group of diseases unrelated in these data to smoking-and comprising $61 \%$ of the total mortality-the death rates of the several and different smoking categories (with the one exception of continuing heavy cigarette smokers) all lie in an exceedingly narrow range. There appears to be no cause of mortality which is lessened by smoking.

If the excess deaths in smokers under the age of 65 years from (a) cancer of the lung, (b) chronic bronchitis and emphysema, and $(c)$ coronary thrombosis without hypertension be taken as attributable to their cigarette smoking, then the total mortality from all causes at ages $45-64$ years is increased thereby by approximately $50 \%$.

One of the striking characteristics of British mortality in the last half-century has been the lack of improvement in the death rate of men in middle life. In cigarette smoking may lie one prominent cause.

This work was made possible by the co-operation of the thousands of doctors who completed our two questionaries, and we are most grateful to them for their assistance. We are also indebted to the many doctors who gave us details of the evidence on which their diagnoses were based; to Dr. J. R. Bignall, who advised on the diagnosis in particularly difficult cases ; to the British Medical Association, who helped in tracing individual doctors ; to the RegistrarsGeneral of the United Kingdom and the Registrars of the General Medical Council and its branch councils in Ireland and Scotland, who provided information about doctors' deaths; and to the com- bined tabulating installation of Her Majesty's Stationery Office, who undertook the mechanical analysis of much of the data. We are grateful also to Miss Margaret Devine, who programmed the more complex data for analysis by the London University Computer Unit's Mercury ; to Mrs. Janet Pixner, who carried out the greater part of the calculations; and to Mrs. Jean Gilliland, who was responsible for the onerous work of maintaining and coding the mass of individual records.

\section{REFERENCES}

Acheson, R. M., and Jessop, W. J. E. (1961). Brit. med. 7., 2, 1108 Anderson, D. O., and Ferris, B. G., jun. (1962). New Engl. Ұ. Med.,

267, 787.
Auerbach, O., Stout, A. P., Hammond, E. C., and Garfinkel, L. (1961). Ibid., 265, 253.

- (1962). Ibid., 267, 111, 119.

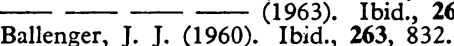

Ballenger, J. J. (1960). Ibid., 263, 832. 206

Brown, R. G., McKeown, T., and Whitfield, A. G. W. (1957). Brit. J. prev. soc. Med., 11, 162 .

Buechley, R. W., Drake, R. M., and Breslow, L. (1958). Circulation, 18, 1085 .

Campbell, A. H., and Lee, E. J. (1963). Brit. 7. Dis. Chest, 57, 113.

Case, R. A. M.' (1954). Brit. med. 7., 2, 987.

and Lea, A. J. (1955). Brit. F. prev. soc. Med., 9, 62

Davies, C. N. (1957). Brit. med. 7., 2, 410.

Doll, R. (1953). Brit. 7. Cancer, 7, 303.

Doll, and Hill, A. B. (1952). Brit. med. 7., 2, 1271

- and Hill, A. B. (1952). Brit.

- (1956). Ibid., 2, 1071

Jones, F. A., and Pygott, F. (1958). Lancet, 1, 657.

Dorn, H. F. (1959). Publ. Hlth Rep. (Wash.), 74, 581.

Doyle, J. T, Dawber, T. R., Kannel, W. B., Heslin, A. S., and Kahn, H. A. (1962). New Engl. f. Med., 266, 796.

Edwards, F., McKeown, T., and Whitfield, A. G. W. (1959). Clin. Sci., 18, 289 .

Eysenck, H. J., Tarrant, M., Woolf, M., and England, L. (1960). Brit. med. F., 1, 1456.

Fisher, R. A. (1957). Ibid., 2, 43, 297.

(1959). Smoking: The Cancer Controversy. Some Attempts to Assess the Evidence. Oliver and Boyd, Edinburgh.

Fletcher, C. M., and Tinker, C. M. (1961). Brit. med. F., 1, 1491.

Goodhart, C. B. (1959). Practitioner, 182, 578 .

Goodhart, C. B. (1959). Practitioner, 182, 578 . 1294.

Hauge, M., and Harvald, B. (1961). Acta genet. (Basel), 11, 372.

Heath, C. W. (1958). Arch. intern. Med., 101, 377.

Higgins, I. T. T. (1957). Brit. med. f., 2, 1198.

Hilding, A. C. (1956). New Engl. 尹. Med., 254, 1155

Karvonen, M., Orma, E., Keys, A., Fidanza, F., and Brozek, J. (1959). Lancet, 1, 492.

Kershbaum, A., Bellet, S., Dickstein, E. R., and Feinberg, L. J. (1961). Circulat. Res. 9,631

Kissen, D. M. (1960a). Hlth Bull. (Edinb.), 18, 38.

- (1960b). Med. Offr, 104, 365.

Konttinen, A. (1962). Brit. med. 尹., 1, 1115.

_ and Rajasalmi, M. (1963). Ibid., 1, 850

Lilienfeld, A. M. (1959). 尹. nat. Cancer Inst., 22, 259

Levin, M. L., and Moore, G. E. (1956). Arch. intern. Med., 98, 129.

Lockwood, K. (1961). Acta path. microbiol. Scand., 51, Suppl. 145, p. 1. Lowe, C. R. (1955). Brit. med. F., 2, 1081

Miall, W. E. (1960). Proc. W.H.O. Czech. Cardiol. Soc. Symp. on Pathogenesis of Essential Hypertension, Prague.

Murphy, D. P., and Abbey, H. (1959). Cancer in Families. Harvard University Press, Cambridge, Massachusetts.

Mustard, J. F., and Murphy, E. A. (1963). Brit. med. F., 1, 846.

Olsen, H. C., and Gilson, J. C. (1960). Ibid., 1, 450.

Oram, S., and Sowton, E. (1963). Quart. F. Med., 32, 115

Oswald, N. C., Harold, J. T., and Martin, W. J. (1953). Lancet, 2, 639.

Pickering, G. W., and Sanderson, P. H. (1945). Clin. Sci., 5, 275.

Pickering, G. W., and Sanderson, P. H. (1945). Clin. Sci., 5, 275.

Pike, M. C., and Roe, F. J. C. (1963). Brit. F. Cancer, 17, 605.
Reid, D. D., and Fairbairn, A. S. (1958). Lancet, 1, 1147.

Reid, D. D., and Fairbairn, A. S. (1958). Lancet, 1, 1147. Public Health Service (1964). Smoking and Health, Public Health
Pmich Service Publication No. 1103. U.S. Govt. Printing Office, Washington.

Roe, F. J. C., and Clack, J. (1963). Brit. F. Cancer, 17, 596.

Royal College of Physicians (1962). Smoking and Health. Pitman, London.

Schwartz, D., Anguera, G., and Lenègre, J. (1961). Rev. franç. Btud. clin. biol., 6, 645 .

Denoix, P. F., and Anguera, G. (1957). Bull. Ass. franç. Cancer, 44, 336.

44, 336. Flamant, R., Lell.

Seltzer, C. C. (1963). F. Amer. med. Ass., 183, 639.

Spicer, C. C. (1964). To be published.

Thomas, C. B. (1960). Ann. intern. Med., 53, 697.

Wynder, E. L., and Bross, I. J. (1961). Cancer (Philad.), 14, 389.

- and Day, E. (1956). Ibid., 9, 86. - and Feldman, R. M. (1957). Ibid., 10, 1300. Graham, E. A., and Croninger, A. B. (1955). Cancer Res., 15, 445.

- Onderdonk, J., and Mantel, N. (1963). Cancer, 16, 1388. 